УДК 339.54

РЕЗУЛЬТАТЫ ЦИФРОВИЗАЦИИ ВНЕШНЕЭКОНОМИЧЕСКОЙ ДЕЯТЕЛЬНОСТИ СТРАН ЮЖНОЙ АЗИИ

${ }^{1}$ Головин Ар.А., ${ }^{2}$ Спицына А.О., ${ }^{3}$ Арепьев Я.А., ${ }^{1}$ Кудинов В.И., ${ }^{1}$ Агарков М.А.

${ }^{\prime}$ ФГБОУ ВО «Юго-Западный государственный университет», Курск,

e-mail:cool.golovin2011@yandex.ru,kvi2002@yandex.ru,agarkovmaxim@mail.ru;

${ }^{2}$ Курский филиал ФГОБУ ВО «Финансовый университет при Правительстве

Российской Федерации», Курск, e-mail: spicyna1984@таil.ru;

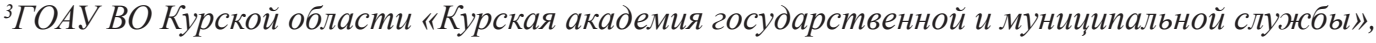

Kурск, e-mail: arepyaroslav@yandex.ru

В данной статье авторами проведено исследование опыта авангарда мировой цифровизации внешнеэкономической деятельности - Республики Корея и Японии. Выявлено, что Республика Корея позже приступила к цифровизации внешнеторговой деятельности, что было вызвано некоторым отставанием в экономическом плане и Корейской войной, затормозившей развитие. Финансирование создания «единого окна» в Японии проводилось полностью за счёт средств бюджета, а в Корее - по форме государственно-частного партнёрства. В дальнейшем оператор системы «единого окна» Японии был приватизирован. Преимуществом «единого окна» Японии стало более полное межведомственное взаимодействие. Опыт двух стран в полной мере сопоставим, так как основные грузопотоки идут морским и воздушным транспортом, в Японии по причине отсутствия сухопутных границ с другими странами, а в Республике Корея по причине закрытия единственной сухопутной границы с КНДР. В целом системы обеих стран претерпели эволюционное развитие, предполагавшее постепенное расширение возможностей, включение новых сервисов, а также присоединение новых государственных органов в рамках межведомственного взаимодействия. Опыт исследованных стран интересен и перспективен для внедрения в практику стран - членов ЕАЭС, однако высокие затраты создания и управления системой «единого окна» по примеру Республики Корея и Японии могут стать останавливающим фактором.

Ключевые слова: цифровизация, внешняя торговля, таможенные органы, внешнеторговые операции, зарубежный опыт, Республика Корея, Япония

\title{
THE RESULTS OF THE DIGITALIZATION OF FOREIGN ECONOMIC ACTIVITY IN SOUTH ASIA
}

${ }^{1}$ Golovin Ar.A., ${ }^{2}$ Spitsyna A.O., ${ }^{3}$ Arepev Ya.A., ${ }^{1}$ Kudinov V.I., ${ }^{1}$ Agarkov M.A.

${ }^{1}$ South-West state University, Kursk, e-mail: cool.golovin2011@yandex.ru, kvi2002@yandex.ru,agarkovmaxim@mail.ru;

${ }^{2}$ Kursk branch of the Financial University under the Government of the Russian Federation, Kursk,e-mail: spicyna1984@mail.ru;

${ }^{3}$ Kursk Region Kursk Academy of State and Municipal Service, Kursk,e-mail: arepyaroslav@yandex.ru

In this article, the authors conducted a study of the experience of the vanguard of global digitalization of foreign economic activity - the Republic of Korea and Japan. It was revealed that the Republic of Korea started the digitalization of foreign trade activities later, which was caused by some lag in economic terms and the Korean War that slowed down the development. Funding for the creation of the «single window» in Japan was carried out entirely at the expense of the budget, and in Korea in the form of public private partnership. Subsequently, Japan's «single window» operator was privatized. The advantage of Japan's «single window» was more complete interdepartmental interaction. The experience of the two countries is fully comparable, since the main cargo flows go by sea and air transport, in Japan due to the lack of land borders with other countries, and in the Republic of Korea due to the closure of the only land border with the DPRK. In general, the systems of both countries have undergone evolutionary development, involving the gradual expansion of capabilities, the inclusion of new services, and the accession of new government agencies as part of interagency cooperation. The experience of the countries studied is interesting and promising for implementation in the practice of the EEU member states, but the high costs of creation and management of the «single window» system, following the example of the Republic of Korea and Japan may become a stopping factor.

Keywords: digitalization, foreign trade, customs authorities, foreign trade operations, foreign experience, Republic of Korea, Japan

Цифровизация, обобщённо, это внедрение цифровых технологий в сферы хозяйственной деятельности. Под цифровыми технологиями принято понимать дискрет- ную систему, в которой происходит кодирование и трансляция информации, позволяющей решать заложенные в неё задачи. Цифровизация стала основным вектором 
развития народного хозяйства с момента широкого распространения персональных компьютеров (ПК) и расширения сети Интернет. Первоначально ПК и сеть Интернет использовались как средство связи, для передачи информации между хозяйствующими субъектами и отдельно между органами государственной власти. Затем взаимодействие стали налаживать между органами государственной власти, хозяйствующими субъектами и физическими лицами. Результаты цифровизации позволили значительно упростить взаимодействие, а скорость и удобство совершения операций стимулировали развитие национальной и мировой экономик.

Внешнеэкономическая деятельность является неотъемлемым элементом глобализации, даже такие закрытые страны, как КНДР и Куба, участвуют в мировой торговле и международном разделении труда. Внешнеэкономическая деятельность является одной из основ капиталистической системы хозяйствования, подразумевающей свободные экономические отношения субъектов как внутри страны, так и за её пределами. Но в то же время внешнеэкономическая деятельность подвержена большему регулированию со стороны государства. Высокая степень регулирования обусловлена необходимостью поддержания отечественного производства, защиты жизни и здоровья населения, охраны окружающей среды, а также пополнения бюджета. Данные моменты определили действия, совершаемые органами государственной власти, при экспортноимпортных операциях.

Таможенный институт призван решать задачи, связанные с внешнеэкономической деятельностью. Таможенные органы совершают операции по оформлению и контролю товаров и транспортных средств, перемещаемых через таможенную границу. В своей работе они взаимодействуют с другими государственными органами, обеспечивающими фитосанитарный, ветеринарный, эпидемиологический контроль, осуществляющими финансовый контроль, контроль перемещения вооружения, взрывчатых веществ, наркотических веществ и их прекурсоров, радиационный контроль и т.д. Взаимодействие таможенных органов, участников ВЭД и иных государственных органов, чьи полномочия распространяются на регулирование внешнеторговых операций, отнимает значительное время и требует значительных затрат как участников ВЭД так органов власти. Цифровизация призвана избавить от избыточных затрат времени и средств на совершение внешнеторговых операций. Основным инструментом, использующим цифровые технологии совершенствования внешнеторговых операций, является «единое окно» - ресурс сети Интернет, позволяющий осуществлять внешнеторговые операции в сети и взаимодействовать не только с таможенными органами, но и с другими органами государственной власти, реализующими полномочия во внешнеэкономической сфере. Идеальный механизм «единого окна» предполагает наднациональное взаимодействие, т.е. взаимодействие отечественных органов государственной власти с органами власти иностранных государств посредством сети Интернет [1, с. 173].

Рассмотренные моменты определили актуальность темы исследования, которая заключается в исследовании передового зарубежного опыта цифровизации внешнеэкономической деятельности.

Целью работы является исследование передового зарубежного опыта цифровизации внешнеэкономической деятельности с позиции оценки развития, организации и взаимодействия заинтересованных участников, а также перспектив заимствования для стран Евразийского экономического союза.

Объектом исследования являются организационно-правовые отношения между органами государственной власти и хозяйствующими субъектами по поводу организации системы регулирования внешнеэкономической деятельности с использованием цифровых технологий.

\section{Материалы и методы исследования}

В качестве материалов исследования использовались зарубежные источники на иностранном языке и их переводные издания. Широко использовались интернетресурсы стран Южная Корея и Япония, а также аналитические и информационные материалы государственных, коммерческих и некоммерческих организаций.

Методическую базу исследования сформировали компаративный и ретроспективный анализ; использовались эмпирический метод, научная абстракция, синтез, индукция и дедукция, а также иные методы, позволившие достичь цели исследования. Для наглядной интерпретации полученных результатов использовался графический метод.

\section{Результаты исследования и их обсуждение}

При разработке направлений повышения эффективности взаимодействия тамо- 
женных органов (ТО) и участников ВЭД, необходимо провести анализ и оценку опыта иностранных государств. Авангардом цифровизации внешнеэкономической деятельности в мире считаются Япония и Южная Корея. Опыт данных стран имеет одинаковую цель, - упрощение внешнеторговых операций, но путь к данной цели Япония и Южная Корея прошли разный.

«Единое окно» повсеместно признается высокоэффективным инструментом по упрощению операций в трансграничной торговле, но при его внедрении и использовании правительства и таможенные службы разных стран мира сталкиваются с большим количеством проблем и преград. Формирование механизма «единого окна» на территории Евразийского экономического союза (ЕАЭС) считается одним из современных приоритетных направлений сотрудничества, в связи с чем возникает необходимость исследования опыта использования этого механизма в зарубежных странах.

С 1992 г. таможенная служба Республики Корея стремилась автоматизировать процесс таможенного оформления товаров с помощью концепции электронного обмена данными (далее - EDI). Основой данной концепции стал «Шестилетний базовый план автоматизации таможни посредством электронного обмена данными» [2, с. 32].

В процессе автоматизации таможенного оформления товаров, посредством перехода к безбумажной торговле, в Республике Корея была разработана Концепция оказания услуг автоматизации торговли и таможенного оформления на основе системы электронного обмена данными. С 1994 г. решения об экспорте и импорте товаров одобрялись Службой таможенного декларирования экспорта посредством EDI. В 1997 г. EDI стал включать возможность возврата излишне уплаченных таможенных платежей при экспорте товаров, а затем в 1998 г. данная возможность стала предусматриваться при совершении импортных внешнеторговых сделок. В 1999 г. была организована информационная система расследования, которая в дальнейшем превратилась в систему управления рисками.

Следующим этапом развития безбумажной торговли в Республике Корея стало перемещение в 2000 г. ЕDI в сеть Интернет. Аналогичные процессы можно было наблюдать в России при переходе в электронном декларировании от ЭД-1 к ЭД-2. Корейская торговая сеть (далее - KTNET) в 2000 г. запустила интернет-систему электронных таможенных платежей. С 2003 г. KTNET стала предусматривать возможность безбумажной торговли через интернет-пор- тал, что позволило пользователям системы отправлять внешнеторговые документы по экспортным и импортным сделкам из любого места мира. Декларация, внешнеэкономический контракт и другие торговые документы загружались в специальную систему посредством сети Интернет, где с ними осуществляли работу таможенные органы и иные уполномоченные органы государственной власти. У пользователей KTNET в 2005 г. появилась возможность заполнения таможенных деклараций в сети Интернет [3].

B результате развития безбумажной торговли в Республике Корея были созданы все предпосылки для полноценного функционирования «единого окна». В 2003 г. в рамках трехлетнего проекта по развитию электронной коммерции была учреждена самостоятельная организация по внедрению и развитию технологий электронной коммерции. В организации были представлены Министерство торговли, промышленности и энергетики Республики Корея, Таможенная служба Кореи (далее - KCS), Корейский институт финансовых телекоммуникаций и клиринга, KTNET и Корейская федерация банков. Результатом деятельности организации стала разработка в 2003 г. и запуск в 2006 г. интернет-платформы безбумажной торговли uTradeHub.

Система «единого окна» Республики Корея представлена на рис. 1.

В апреле 2016 г. KCS приступила к реализации таможенной концепции четвёртого поколения, разработка которой велась с 2013 г. Новая система таможенного оформления UNI-PASS показала лучшие характеристики по сравнению с третьим поколением. Основные улучшения касались бизнес-процессов, простого в использовании интерфейса, новых мобильных инструментов и технологий аналитики информации, принятия модели данных и стандартов корейского правительства в области ИКТ, а также внедрения предварительного информирования, контроля и мониторинга системы и услуг.

Основное финансирование создания «единого окна» безбумажной торговли Республики Корея осуществлялось по схеме B2G. Первоначальное финансирование создания «единого окна» было предоставлено государственным грантом, в то время как процесс совершенствования операций, системы управления и разработка новых подходов были переданы частному бизнесу.

В настоящее время UNI-PASS и uTradeHub предлагают безбумажную торговую среду, которая охватывает торговые экспортные и импортные операции Республики Корея. 


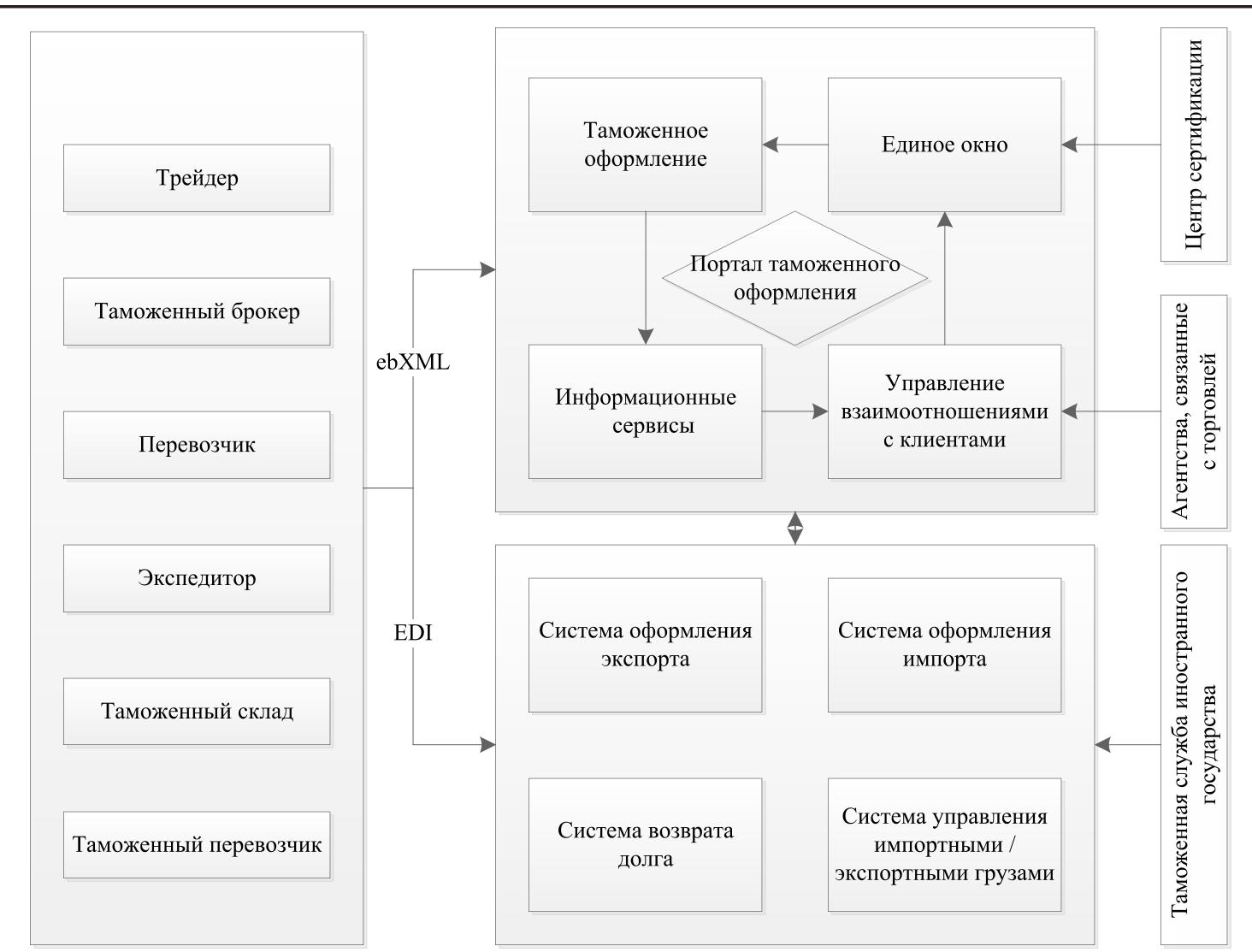

Рис. 1. Система «единого окна» Республики Корея [4]

Тем не менее в Республике Корея нет сильного институционального механизма для согласования и координации данных двух огромных цифровых платформ. Государственный Совет, по данным электронной коммерции, говорил о важности единой системы управления, однако решение так и не было реализовано. Отсутствие координирующего государственного органа в соответствии с упрощением торговых операций может послужить поводом для конфликта между двумя платформами, а кроме того приведёт к дополнительным бюджетным расходам, вызванных дублирующей работой. Для оптимального функционирования «единого окна» и вторичного использования коммерческой информации необходима единая система координации для обеих платформ.

Республика Корея реализует инициативы трансграничной безбумажной торговли в тесном сотрудничестве с соседними странами. Обмен электронными документами налажен с Китайской Республикой (Тайвань), а упрощённый обмен таможенной информацией - с Китайской Народной Республикой (КНР). Обмен внешнеторговой информацией является основой безбумажной трансграничной торговли. Однако двусторонние соглашения могут оказаться несовместимы с другими заключёнными договорами, что может ограничить возможности соглашений и создать сложности в их реализации. Поскольку национальные экономики участвуют в торговых сделках с другими государствами, двусторонний подход может значительно ограничить возможности реализации «единого окна» и упрощения торговых операций. Кроме того, страны не принимают обязательств относительно того, чтобы двусторонние соглашения были совместимы между собой и учитывали интересы стран-партнёров. Данная ситуация вызвана тем, что различные страны-партнёры могут требовать разные уступки и накладывать свои ограничения в товарообменных операциях.

Япония, в отличие от Республики Кореи, начала разрабатывать систему «единого окна» в 1977 г. [5]. Система «единого окна» Японии получила название Nippon Automated Cargo Clearance System (Автоматизированная система таможенной очистки Nippon) (далее - NACCS), увидела свет в 1978 г. Nippon переводится как «место, где восходит Солнце» и служит для обозначения страны Япония. NACCS - это компью- 
терная система онлайн-обработки административных и таможенных документов, предназначенная для обслуживания частных лиц, для прибывающих и отправляющихся судов и самолётов, а также импортных и экспортных грузов. Далее система NACCS превратилась в систему JAPA SW. Изначально NACCS начала свою работу в 1978 г. как Air-NACCS в международном аэропорту Нарита, обслуживая воздушные перевозки, в том числе торговые импортные поставки. Область действия Air-NACCS позже была расширена за счёт обработки деклараций экспортных поставок и уведомлений о прибытии/отбытии самолётов, а затем распространена на другие аэропорты по всей Японии. В 1991 г. действие системы NACCS было расширено на морские перевозки. Впервые Sea-NACCS была внедрена в порту Токио-Иокогама. В 1999 г. возможности системы Sea-NACCS были расширены и стали включать все таможенные операции. Затем опыт успешного использования Sea-NACCS был перенесён на все порты страны. Система Port EDI Министерства земельных ресурсов, инфраструктуры, транспорта и туризма, успешно была включена в систему Sea-NACCS в октябре 2008 г.

Пользуясь законодательными возможностями Конвенции по облегчению международного морского судоходства 1965 г. (Конвенция FAL), в ноябре 2005 г. были значительно упрощены торговые процедуры в отношении грузов, прибывающих морским транспортом. Количество обязательных форм было сокращено вдвое, а перечень используемых терминов - в три раза. Пять обязательных для захода в порт форм были объединены в одну, что значительно упростило административные формальности. Принятые нововведения позволили значительно повысить эффективность обработки информации. Данные, введённые один раз, стали использоваться многократно, что позволило избежать дополнительных затрат времени на повторный ввод информации, а следовательно, и вероятность совершения ошибок.

В декабре 2005 г. на Конференции по связи Главное информационное агентство страны приняло «План оптимизации организаций и компьютерных операций, связанных с экспортно-импортным оформлением, в том числе осуществляемом в международных аэропортах». Данный план предполагал обновление «единого окна» до следующего поколения.

В мае 2007 г. была подготовлена Программа оптимизации торговых мер - «Инициатива "Азиатские ворота"», которая получила поддержку руководства страны. Целью Инициативы стала оптимизация таможен- ных и сопутствующих операций в целях укрепления международного транспортного потенциала страны. Основные компоненты следующего поколения «единого окна» Японии предполагали полную интеграцию NACCS и Port EDI, создание «единого окна» для воздушных грузоперевозок и единого портала для оказания государственных услуг в области внешнеторговой деятельности.

В соответствии с планом реализации Инициативы в октябре 2008 г. были интегрированы NACCS и Port EDI. В феврале 2010 г. модернизированные Air-NACCS и Sea-NACCS вошли в единую систему NACCS. Также в 2010 г. в NACCS была интегрирована «Электронная система управления торговлей» с открытой сетью JETRAS Министерства экономики, торговли и промышленности. JETRAS осуществляла контроль внешнеторговых потоков. Интеграция необходимых для оптимального функционирования «единого окна» систем завершилась в 2013 г. включением в NACCS единого портала Министерства здравоохранения, труда и социального обеспечения, а также автоматизированной системы Карантинной инспекции животных, управляемой Министерством аграрного, лесного и рыбного хозяйства (рис. 2).

Пользователями услуг NACCS и «единого окна» выступают как частные, так и государственные сектора экономики. Координация между заинтересованными участниками торгового процесса осуществляется с помощью технических характеристик системы. C данной целью администрация NACCS принимала участие и организовывала форумы для обсуждения решений, наиболее отвечающих целям всех заинтересованных участников процесса. $\mathrm{C}$ целью разработки условий и спецификаций системы были сформированы рабочие группы, включавшие представителей органов государственной власти, предпринимательские структуры и частных лиц. В соответствии с Планом оптимизации экспортно-импортных операций и портовых процедур от 2006 г. правительство Японии обеспечило межведомственную координацию с целью исследования требуемых методик для интеграции административных систем. Цели межведомственной работы состояли в достижении большей эффективности системы при реализации принципов «единого окна», а также в повышении удобства для пользователей. В настоящее время в рамках NACCS осуществляется межведомственное взаимодействие следующих органов власти:

- Министерства экономики, торговли и промышленности; 


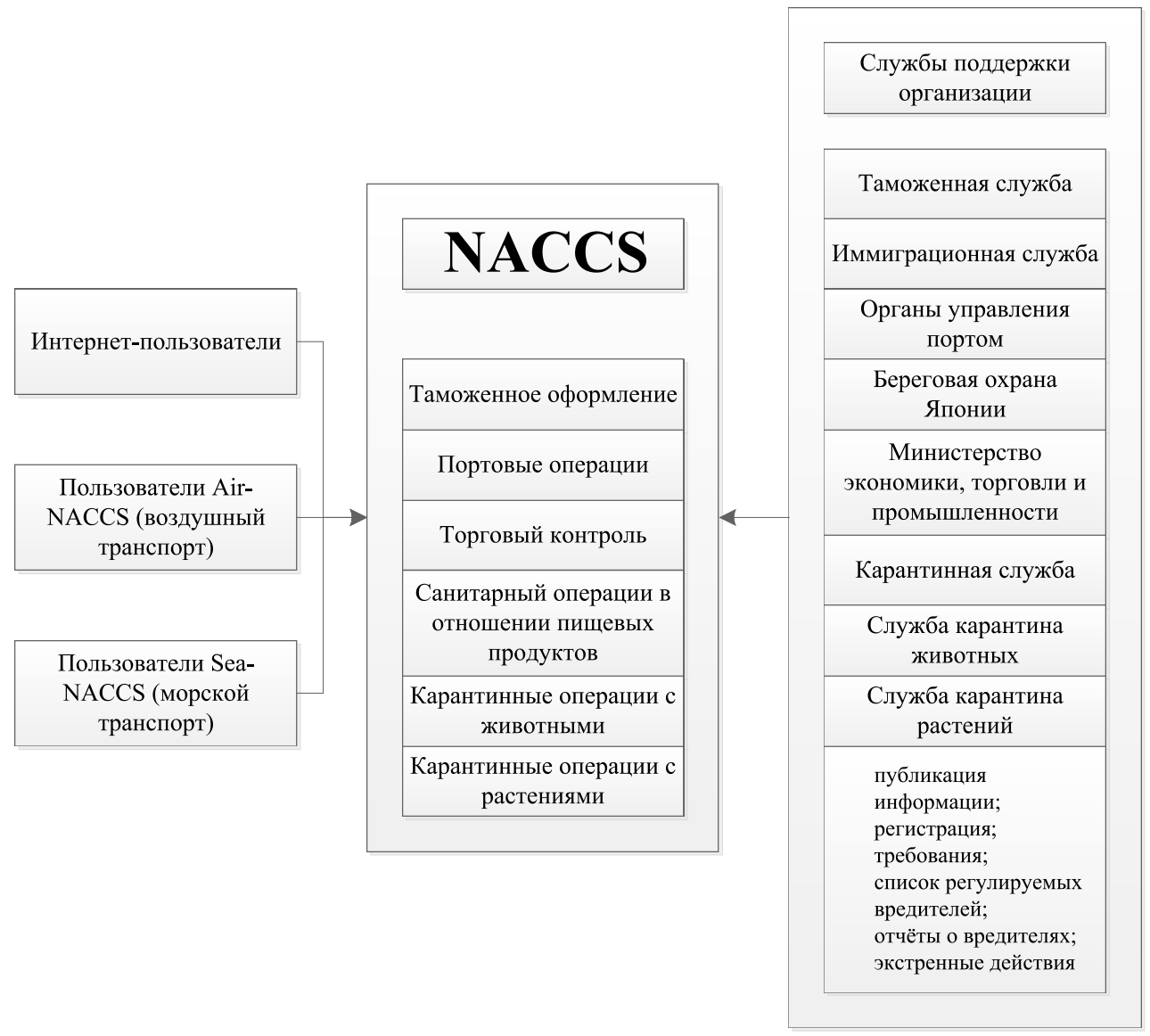

Рис. 2. Система «единого окна» Японии [6]

- Министерства сельского, лесного и рыбного хозяйства;

- Министерства здравоохранения, труда и социального обеспечения;

- Министерства финансов;

- Министерства юстиции;

- Министерства земельных ресурсов, инфраструктуры, транспорта и туризма.

Финансирование разработки, эксплуатации и модернизации NACCS осуществлялось соответствующими министерствами, однако основным источником финансирования стало Министерство финансов Японии. NACCS находится под контролем единственного акционера, которым является Правительство Японии. Однако в 2016 г. началась приватизация, в рамках которой предполагалось реализовать часть акций «Единого окна». Управление и эксплуатацию системы NACCS осуществляет Центральный аппарат NACCS.

Помимо финансирования кардинальных изменений NACCS, которое осуществляется государственными ведомствами, необходимо финансирование текущей деятельности. Источниками такого финансирования являются плата за пользование системой таможенными органами Японии и сборы за совершение таможенных операций, уплачиваемые участниками внешнеэкономической деятельности. При этом за некоторые операции в системе NACCS плата не предусмотрена. Так бесплатной предоставляемой услугой является предварительное информирование.

Важной особенностью является то, что использование сервисов NACCS не является обязательным. Участники ВЭД сохранили возможность воспользоваться традиционными бумажными формами совершения таможенных операций. Тем не менее более $98 \%$ всех таможенных операций осуществляется в рамках системы NACCS. Практика показала, что использование NACCS значительно сократило время совершения таможенных операций, а межведомственное взаимодействие упростило работу органов государственной власти. Участники ВЭД в свою очередь значительно сократили затраты средств и времени на таможенную очистку грузов, что положительно сказалось не только на деятельности участников ВЭД но и в целом на внешней торговле. 


\section{Заключение}

Таким образом, рассмотрев опыт двух южноазиатских государств, являющихся авангардом цифровизации в мировой торговле, можно сделать вывод о целесообразности его использования в ЕАЭС. Важными отличиями двух стран стало то, что Южная Корея осуществляла цифровизацию по схеме государственно-частного партнёрства, а Япония - полностью за счёт государства. В то же время Япония создала более полную систему межведомственного взаимодействия, чем Республика Корея. Успешный опыт цифровизации рассмотренных стран показал свою эффективность в части упрощения международной торговли и снижения затрат совершения внешнеторговых сделок.

Публикачия подготовлена в рамках Государственного задания Министерства науки и высшего образования Российской Федерации (тема № 1.13.20Ф «Кониептуальные основы обеспечения экономической безопасности Российской Федерации в условиях ичифровизации: контуры пространственных преобразований»).

\section{Список литературы}

1. Солодухина О.И. Таможенно-тарифные инструменты регулирования международной торговли в механизме обеспечения национальной безопасности России // Фундаментальные исследования. 2020. № 11. C. 173-178. DOI: $10.17513 /$ fr.42894.

2. Головин А.А., Карпова О.И., Левкина В.С. Исследование опыта Республики Корея в сфере цифровизации процесса совершения внешнеторговых операций // Фундаментальные исследования. 2021. № 3. С. 32-37. DOI: 10.17513/fr.42976.

3. Система «единого окна» Республики Корея. Таможенная служба Республики Корея. Июль 2010 г. ГЭлектронный pecypc]. URL: https://www.unece.org/fileadmin/DAM/ cefact/single_window/sw_cases/Download/Korea_Customs RUS.pdf (дата обращения: 02.11.2021).

4. uTrade Hub - Korea s National Single Window [Электронный ресурc]. URL: https://present5.com/u-trade-hub-korea-s-national-single-window/ (дата обращения: 02.11.2021).

5. Japan's Development of a Single Window - Case of NACCS [Электронный pecypc]. URL: https://www.unescap. org/sites/default/files/brief6.pdf (дата обращения: 02.11.2021).

6. Single Window System in Japan Masaki Okamoto Customs [Электронный ресурc]. URL: https://slidetodoc.com/single-window-system-in-japan-masaki-okamoto-customs/ (дата обращения: 02.11.2021). 